\title{
Stereoselctive Recognition of Vicinal Diamines with a Zn(II) Complex
}

\author{
Woosung Kim, Soon Mog So, Leonid Chagal, Alan J. Lough, B. Moon Kim* \\ and Jik Chin ${ }^{*}$
}

\section{Supporting Information}

\section{CONTENTS}

${ }^{1} \mathrm{H}$ NMR of matching complex with dpen ...........................................

${ }^{1} \mathrm{H}$ NMR of matching complex with dach ......................................

Table of energies for computation of matching and mismatching complexes ........S-4 


\section{Figure S1}

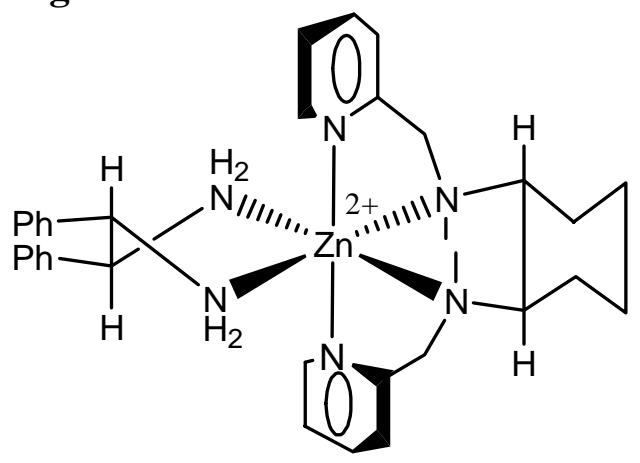

$[((R, R)-\mathbf{L}) \mathrm{Zn}(\mathrm{II})((R, R)-d p e n)]$

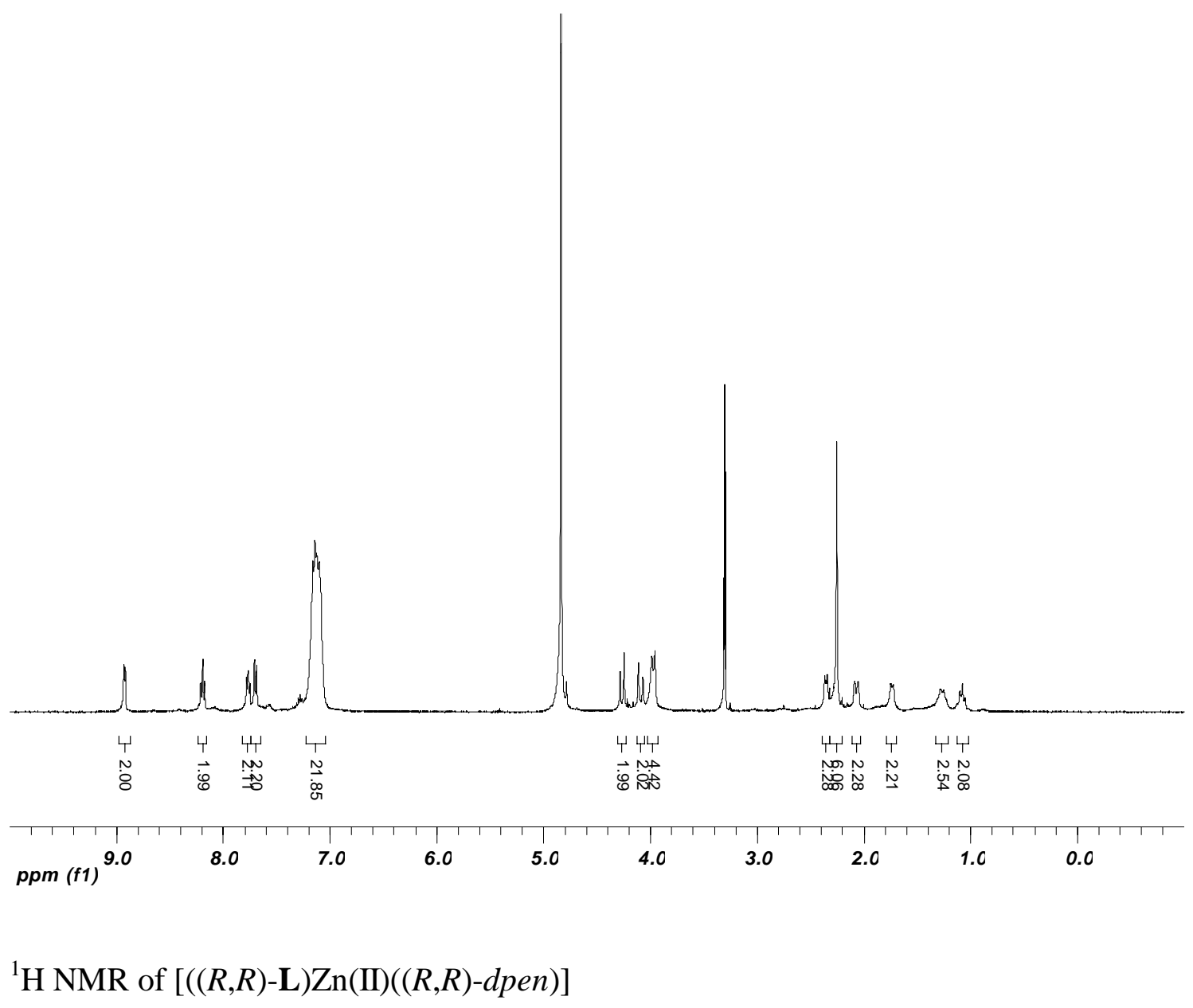


Figure S2

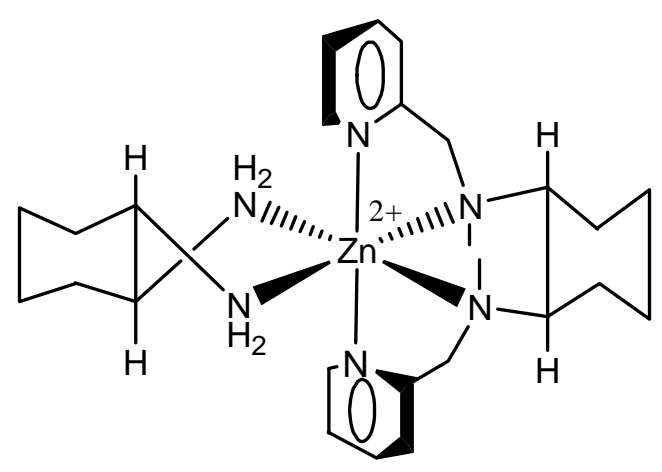

$[((R, R)-\mathbf{L}) \operatorname{Zn}(\mathrm{II})((R, R)-$ dach $)]$

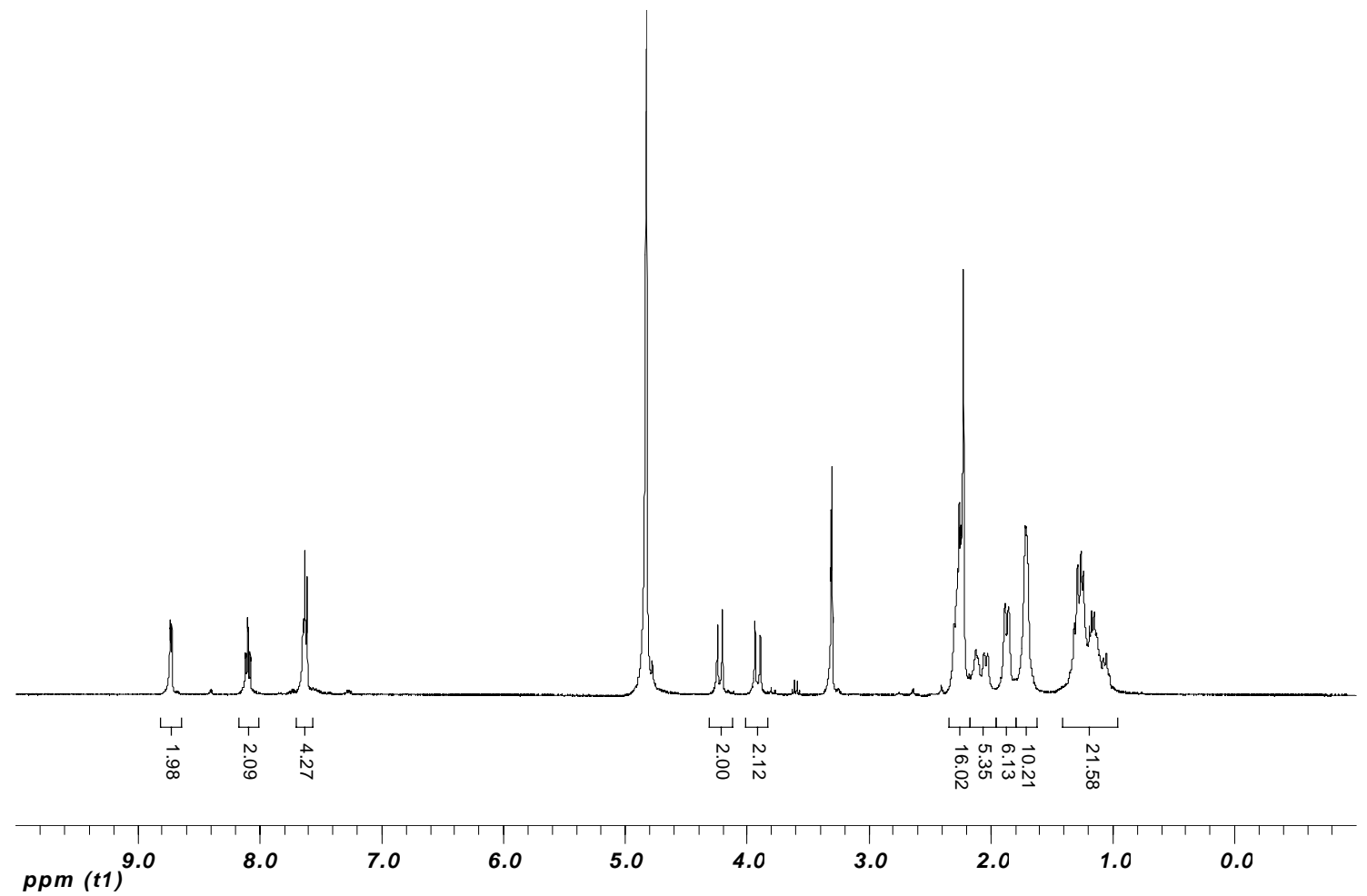

${ }^{1} \mathrm{H}$ NMR of $[((R, R)-\mathbf{L}) \mathrm{Zn}(\mathrm{II})((R, R)-$ dach $)]$ 
Energies of Zn(II)-diamine complex
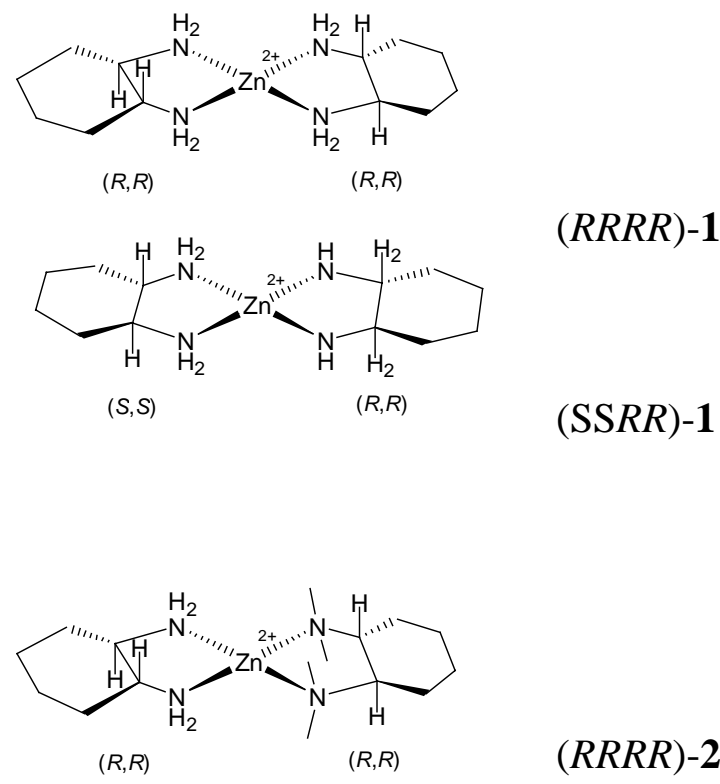

$(R R R R)-2$
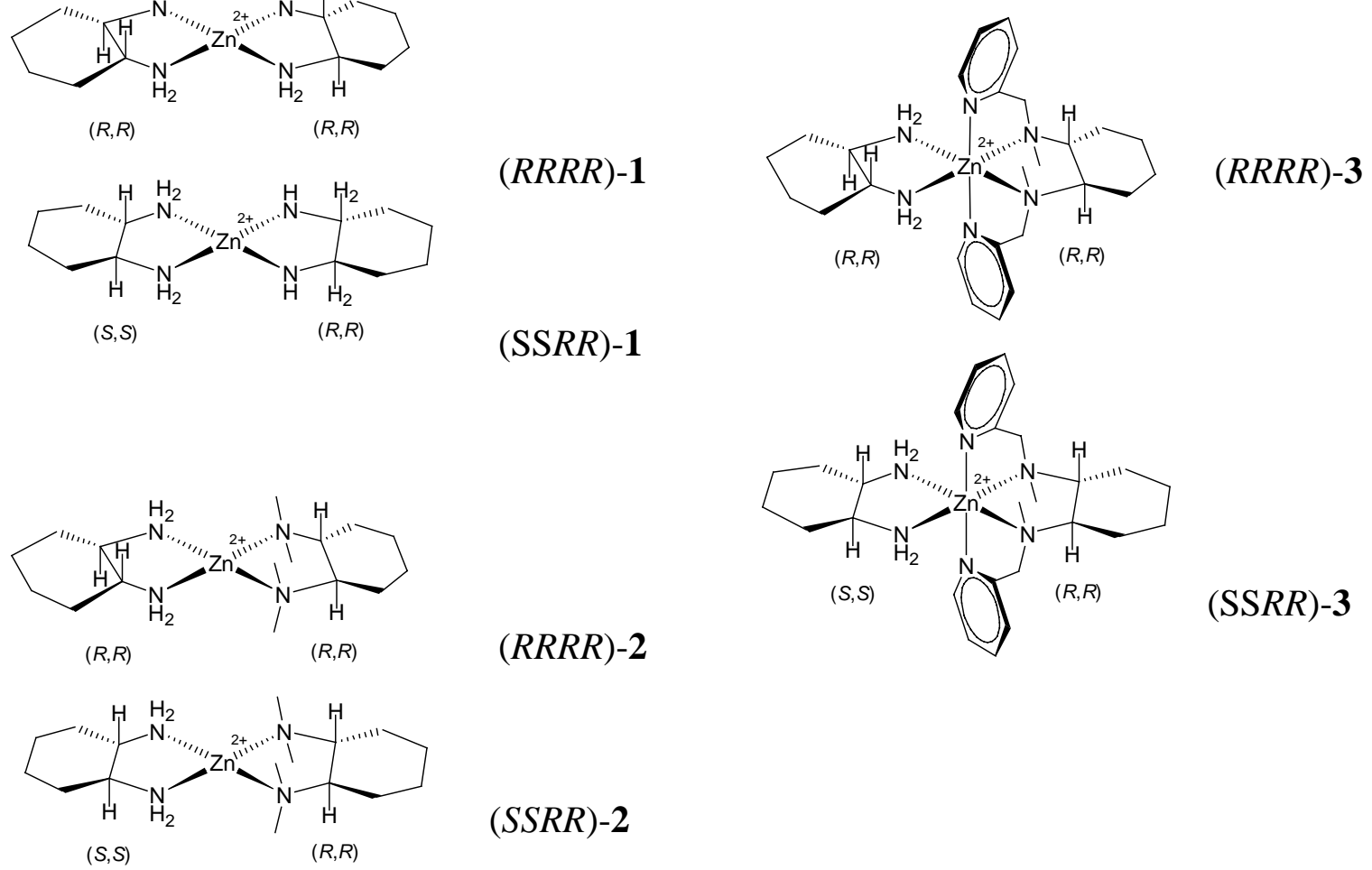

$(\operatorname{SSRR})-\mathbf{2}$

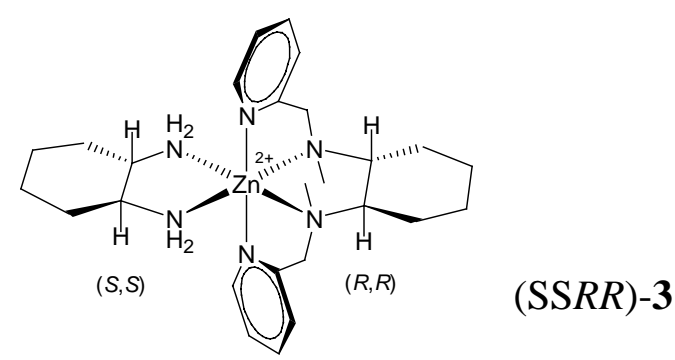

Table S1. Relative energies of the stereoisomers in $\mathrm{kcal} / \mathrm{mol}$.

\begin{tabular}{|c|c|c|c|}
\hline $\mathrm{E}\left(\mathrm{E}_{\mathrm{rel}}\right)$ & $\mathrm{MMFF}$ & $\mathrm{PM} 3$ & $\mathrm{DFT}\left(\mathrm{B} 3 \mathrm{LYP} / 6-31 \mathrm{G}^{*}\right)$ \\
\hline$($ RRRR $)-\mathbf{1}$ & $(0.0)$ & $(0.0)$ & $(0.0)$ \\
$($ SSRR $)-\mathbf{1}$ & $(0.9)$ & $(0.1)$ & $(0.2)$ \\
\hline$($ RRRR $)-\mathbf{2}$ & $(0.0)$ & $(0.0)$ & $(0.0)$ \\
$($ SSRR $)-2$ & $(2.2)$ & $(0.5)$ & $(0.5)$ \\
\hline$(R R R R)-3$ & $(0.0)$ & $(0.0)$ & $(0.0)$ \\
$(S S R R)-3$ & $(4.3)$ & $(2.1)$ & $(1.2)$ \\
\hline
\end{tabular}

